\title{
PARTY FORMATION AND COALITIONAL BARGAINING IN A MODEL OF PROPORTIONAL REPRESENTATION*
}

\author{
January 28, 2004
}

\begin{abstract}
We study a game theoretic model of a parliamentary democracy under proportional representation where 'citizen candidates' form parties, voting occurs and governments are formed. We study the coalition governments that emerge as functions of the parties' seat shares, the size of the rents from holding office and their ideologies. We show that governments may be minimal winning, minority or surplus. Moreover, coalitions may be 'disconnected'. We then look at how the coalition formation game affects the incentives for party formation. Our model explains the diverse electoral outcomes seen under proportional representation and integrates models of political entry with models of coalitional bargaining.
\end{abstract}

\author{
Siddhartha Bandyopadhyay \\ Mandar Oak \\ Dept of Economics, \\ Department of Economics, \\ University of Birmingham, \\ Williams College, \\ Birmingham B15 2TT, U.K. \\ Williamstown, MA 01267 \\ e-mail: s.bandyopadhyay@bham.ac.uk \\ e-mail: moak@williams.edu
}

Key words: proportional representation, party formation, coalitions JEL classification: C72, D72, H19

* We thank Samrat Bhattacharya, Eric Bond, Stephen Coate, James Jordan, Vijay Krishna, Tamar London, Antonio Merlo, Neil Wallace, and participants at several conferences and seminars for comments and especially Kalyan Chatterjee and Tomas Sjöström for endless discussions and suggestions. All remaining errors are ours. 


\section{INTRODUCTION}

In democracies that use proportional representation (PR), it is unusual for a single party to control more than half the seats in parliament. In a study of 313 elections in 11 democracies in Europe (see Diermeier and Merlo (2001)) from 1945-1997, it was found that only 20 of the elections returned a single party with more than half the seats in parliament. Hence, in such democracies minority and coalition governments are more prevalent. Moreover, coalition governments differ in the number of participants as well as the ideological cohesion of their members. For example, in a study of fifteen European democracies in the post war period, Gallagher, Laver and Mair (1995) find that about 35\% of coalitions were minimal winning, 36\% were minority coalitions while the rest of the coalitions $(29 \%)$ were surplus coalitions. Laver and Schofield (1990) and Indridason (2001) report instances of ideologically disconnected coalition governments being formed over the same time period in Europe.

The recent game theoretic models of PR, notably Diermeier and Merlo (2000) and Baron and Diermeier (2001), (collectively referred to as BDM) employ the efficient bargaining approach to coalition politics to provide an explanation for the size diversity of coalitions. According to this approach, the party in charge of putting together a coalition (called the formateur) can buy the support of other parties by adapting a compromise policy position or by making side payments in return for support. Using this they are able to generate equilibrium governments which can be minority, minimum winning or surplus. This is a major point of departure from the previous theoretical literature since Riker (1962) which had consistently predicted minimum winning coalitions in equilibrium. However, these recent papers do not consider the issue of disconnected coalitions ${ }^{1}$. They also do not look at whether their results are consistent with endogenous party entry.

\footnotetext{
${ }^{1}$ Brams et al (2001) is one of the few papers which explicitly addresses this issue.
} 
In this paper we construct a game theoretic model of PR which endogenizes party formation, voting as well as coalitional politics. Our paper shares some features with the aforementioned literature in that we also use the formateur selection procedure ${ }^{2}$ but precludes the possibility of efficient bargaining (in particular, of being able to make unlimited side transfers) or the ability to be able to commit to a policy at the government formation stage. Instead, we assume, that under a coalition government, the implemented policy is approximated by the seat-weighted average of the ideal policies of the coalition partners and each party in the coalition receives a share of power (to be interpreted as rents from office or directed transfers in the paper) in proportion to its seats. This approach allows us to formalize the issue of how party entry and government formation are affected by the relative importance of ideology to rents from office. In doing so, we generate a number of refutable predictions about the role of policy motivation vis-a-vis political power in the determination of government formation as well as political party formation.

The particular assumption about the bargaining outcome has strong empirical support. Empirical studies of power sharing among coalition partners (see Browne and Fendreis (1980) and Laver and Schofield, (1990)) have found substantial evidence that coalition partners share cabinet portfolios in proportion to their relative seat shares. Since a large bulk of political power is vested in various ministerial offices, the politician in charge of a particular ministry is entitled to that power as well as the right to make a policy in the relevant area.

Our second point of departure from the previous literature concerns our treatment of the status-quo in the event of the failure to form a government. We assume that in the event that the attempts at government formation fail, a consensus government comprised of all the parties is formed. Under such government, the implemented policy is the seat-weighted average of the ideal points all the members of the legislature

\footnotetext{
${ }^{2}$ Ansolabehere et al (2003) provide empirical support for the use of such models
} 
and the political power is shared in proportion to the seats. Baron and Diermeier, on the other hand, assume an exogenously given status quo while Diermeier and Merlo assume it to be equal to the ideal point of one of the parties.

The basic structure of our model can be described as follows: there is a polity comprised of groups of citizens who share policy preferences. Each group decides whether or not to form a political party in order to gain representation in the legislature. Election takes place between the contesting parties and each party gets seats in the parliament equal to its vote share. This is followed by the process of government formation. If there exists a party that receives absolute majority, then it is selected as the formateur, otherwise each party is probabilistically chosen to be the formateur with the recognition probability equal to its seat share. The formateur invites any subset of parties in the legislature to form the government. ${ }^{3}$ If all the invitees agree to join the government and if the prospective government wins the backing of a majority of legislators, then the government assumes office. Otherwise a caretaker government is instituted. The policy choice and the power sharing arrangement between the member parties of a government is as described in the earlier paragraph. To sum up, we model the system of PR by integrating the 'citizen-candidate' approach a la Besley and Coate (1997) and Osborne and Slivinski (1996) with a variant of the coalition formation literature.

We now summarize our main results. At the coalition formation stage, we show how the equilibrium nature of coalitions varies both with the choice of formateur as well as with changes in the value of ideology to rents from office. For a symmetric three party case, we completely characterize the equilibrium coalitions. In particular, we see that there is a non monotonic relation between rents from office and connected coalitions. The other cases of interest we discuss is where there is a large centrally located party with two smaller parties on either side and another where the two

\footnotetext{
${ }^{3}$ We do not preclude the possibility that the formateur may invite a subset of parties that does not include itself.
} 
smaller parties are close to each other. We show how this can lead to disconnected coalitions, the two small parties by leaving the large party out can appropriate more rents for themselves. A general result that we get is that when the rents from office are large enough, equilibrium governments are minimal winning though not minimum size. At intermediate ranges (of the value of rents from office) we get the various kinds of coalitions seen in democracies under PR. We then do a two dimensional analogue with BDM and find that for their symmetric three party case we get minimum winning coalitions under the assumptions in our model. The difference stems from the fact that their results (on equilibrium coalition choice) are driven only by the position of the (exogenously given) status quo and choice of formateur while our results also depend on the ideological closeness of the parties as well as the trade-off between rents and ideology. We then examine what incentives the coalition formation procedure gives ideological group to form parties. We find that there exists an equilibrium of the political game which has the median group (when it is unique) being the only group to stand for elections and under some configurations, we show that this could in fact be the unique equilibrium. Hence, this is contrary to the Duvergerian prediction (see Duverger (1964)) ${ }^{4}$ that PR promotes more party formation than does Plurality voting. We further show how political competition can increase with increases in the value placed to rents from office. In particular, beyond a certain value of the rents, we get a (non unique) political equilibrium where all the ideological groups contest for elections.

The next section discusses some more papers which are related to our work. This is followed by presenting the model, solving the legislative game and then solving the entire political game. A comparison is done with the BDM papers using a two dimensional policy space, followed by a robustness analysis by looking at how sensitive

\footnotetext{
${ }^{4}$ See Feddersen (1992), Fey (1997) and Palfrey (1989) for formalizations of the Duvergerian hypothesis that Plurality Rule leads to two party rule.
} 
our results are to the way we model the coalition formation procedure. The final section discusses the empirical relevance of our model and concludes.

\section{RElated Literature}

Our work is related to several strands in the literature, particularly with several papers on coalitional bargaining, party positioning and endogenous party formation. It also draws on the insights provided by classic works on electoral systems, the activist literature on PR (see Barber (1999) for example ) and several case studies which throw light on actual coalitional structure.

The study of what type of coalitions will form in equilibrium dates back to Riker (earlier cit.). However, the concern in Riker's work is with the division of a fixed 'pie' which members of the winning coalition are entitled to. Hence, he predicts a minimum winning coalition i.e. the minimal winning coalition made of the smallest number of members. ${ }^{5}$ When ideology is considered there are no longer compelling reasons to predict a minimal winning coalition. Instead, following Axelrod (1970), the natural thing to predict would be a 'minimum winning connected' coalition - i.e. a coalition that does not leave out a partner who is in between two coalition partners on the ideological dimension. As pointed out, until the papers by BDM, most of the theoretical papers did make such predictions (see Austen Smith and Banks (1988), Baron (1989, 1991,1998) and Lupia and Strom (1995) for instance).

There are also a fair number of models of party formation/strategic entry, starting from the 'citizen candidate' models of endogenous candidate entry to more recent papers by Riviere (2000), Morelli (2001) and Osborne and Tourky (2002) (in the recent papers a distinction is made between a candidate and a party). ${ }^{6}$ These papers either

\footnotetext{
${ }^{5}$ For some of the theoretical papers on coalition formation both with a constant pie as well as a non constant sum pie see Ray and Vohra (1997) and the references in the survey by Bloch (1997)

${ }^{6}$ In recent papers by Levy (2002) and Jackson and Moselle (2002) the role of a party when the space is multidimensional rather than unidimensional is analyzed. For a recent survey on coalitions
} 
assume that the winner is selected by plurality rule or they model the post election policy outcome as a majority rule game, thus missing one of the most important aspects of PR which is coalition formation. There are also papers dealing with strategic entry under more general outcome functions most notably Dutta, Jackson and LeBreton (2000) but the generality of the paper does not allow them to generate any sharp predictions except that under complete information at least one player (candidate) will behave strategically.

The fact that PR promotes diversity has been made by Ortuno Ortin (1997). The paper assumes that the policy is a weighted average of the two parties policy with the weights being proportional to seat shares. The main aim is to provide an explanation of why policies pursued might deviate from the median voter's position. Hamlin and Hjortland (2000) integrate this approach with the citizen candidate literature and De Sinopoli and Iannantuoni (2001) consider model with non strategic parties but strategic voters. Both papers predict two parties under proportional representation contrary to empirical evidence. Moreover, the assumption of vote weighted average does not capture the institutional details of coalition formation and government policy making which is an important aspect of democracies under PR.

A more complete analysis of the electoral process has been made by Austen Smith and Banks (earlier cit.), Baron (1993) Roemer (2001) and Baron and Diermeier (earlier cit.). Baron and Diermeier also note that with 'strategic voting' minority parliaments may form in equilibrium and voters do not always vote for the party closest to their ideal point. The first result is of interest as it provides a justification for dealing with the coalition formation stage under a minority parliament. These papers do not deal with party formation and their parties are only endogenous in the sense that they choose positions.

and party formation, see Dhillon (2003) which also discusses some other recent work on political parties and coalitions. 
In summary, we differ from these papers in two major ways. First, we make different assumptions about coalitional bargaining (in particular, by assuming no commitment and non transferable utility). Second, we integrate the 'institution free' citizen-candidate approach to politics with the rich institutional details of parliamentary democracy under PR.

\section{THE MODEL}

In this section we formalize the political process under PR. We denote by $\mathcal{N}=$ $\{1,2, \ldots, N\}$ the set of groups of citizens in the polity where $1 \leq N<\infty$. Let $N_{i}$ denote the measure of citizen belonging to group $i$. Let $\mathcal{X}$ denote the policy space. The payoff of a (representative)citizen belonging to group $i$ is denoted by

$$
-u\left(\left|x_{i}-x\right|\right)+T
$$

where $x \in \mathcal{X}$ is the policy implemented, $x_{i}$ is the ideal policy of party $i$ and $T$ is the transfer of money received by the citizen. The interpretation of $T$ is the amount of directed transfer made to that group as opposed to the policy which has a public good interpretation. We shall throughout assume that a group which is a part of the government receives a transfer $\lambda P$ where $\lambda$ is the relative size (seat share) of the group in terms of the number of parties in the government. This is the main distinction from being in government and out of government Only members of a government are able to hold ministries and hence make directed transfers to their own groups. This is the particular way we interpret the rents from office and following the strong empirical evidence (as discussed in the Introduction) we assume the ministries (which we assume is vested with the ability to make these transfers) to be split according to 
party size. ${ }^{7}$ We assume that $u(0)=0, u^{\prime}>0, u^{\prime \prime} \geq 0$. The political process can be described by the following four stages.

(1) Candidate Entry Each group simultaneously decides whether or not to contest the elections. There is a cost $\delta>0$ of contesting the elections. Let $e_{i}=1(0)$ indicate that group $i$ contests (does not contest) the elections. Hence, given an entry profile $e=\left(e_{1}, e_{2}, \cdots, e_{N}\right)$, the set of parties contesting an election can be denoted by $\mathcal{C}(e)=\left\{i \in \mathcal{N}: e_{i}=1\right\}$.

(2) Elections Citizens simultaneously vote over the set of contesting parties $\mathcal{C}(\neq \emptyset)$. We assume throughout this model that voting is costless and each citizen votes for the party that is closest to his ideal policy. Upon elections, each party receives seats in the parliament in proportion to its relative vote share. In reality there are minimum floor requirements and the integer constraints that must be taken into account. In our model we abstract from these considerations.

(3) Government Formation Let $\left(C, S_{i},\left\{x_{i}\right\}\right)$ denote a parliament comprised of $C(>0)$ parties where $S_{i}$ denotes party $i$ 's seat share and $x_{i}$ its ideal point. The process of government formation is comprised of three stages: formateur selection, proto-coalition formation and the vote of confidence.

(a) Formateur Selection If there is a party $k$ such that $S_{k}>\frac{1}{2}$, then party $k$ is asked to be the formateur. If there is a hung parliament, i.e., if $S_{i} \leq \frac{1}{2}$ for all $i \in \mathcal{C}$, then each party is asked to become the formateur with probability $S_{i}$. The formateur selection process described here (variously

\footnotetext{
${ }^{7}$ Note that we could alternately have assumed that people care for policy and rents (or directed transfers) in the ratio $\alpha$ and $1-\alpha$. Hence, payoff for a citizen of group $i$ can be written as $-\alpha u\left(\left|x_{i}-x\right|\right)+(1-\alpha) T$. The comparative statics that we do would have been in terms of the marginal rate of substitution between policy benefits and rents. This makes no qualitative change, so we keep the simpler formulation.
} 
called proportional selection or random recognition) seems to fit the data well (see Diermeier and Merlo (2001)).

(b) Proto-Coalition Selection The formateur asks any subset of parties in the legislature, $D$, to form a government. $D$ is called the proto-coalition. All the members of the proto-coalition must simultaneously decide whether or not to accept the offer. If the offer is unanimously accepted, then $D$ goes on to seeks the vote of confidence, otherwise a caretaker government is instituted.

(c) Vote of Confidence If a proto-coalition decides to accept the formateur's offer, it must seek the vote of confidence from the legislature. Each member of the legislature simultaneously votes to approve or to disapprove the proto-coalition. If the proto-coalition wins more than $50 \%$ of the votes, then it goes on to form a government, otherwise a caretaker government is instituted.

(4) Policy Selection Let $D$ denote the government in office. Depending upon the outcome of the government formation stage, there could either be a single party government, coalition government or a caretaker government in power. There are two cases to consider.

- Single Party or Coalition Government: Let $\pi_{i}$ denote the relative seat share of party $i$ in the government. We assume that the policy chosen by such a government is given by $\sum_{k \in D} \pi_{k} x_{k}$ and each member of each party in power gets a transfer equal to $\frac{1}{\sum_{i \in D} \pi_{i}} P$.

- Consensus Government: In case of a caretaker government, the policy implemented is given by $\sum_{i \in \mathcal{C}} S_{i} x_{i}$ and each member of the legislature gets a transfer $P$. In other words, a caretaker government is the same as a consensus government formed by all parties in the legislature.

We assume that if no group decides to form a party, then each citizen receives a payoff $u_{\emptyset}$. 


\section{Solving the Legislative Model}

We will solve the game backwards. Thus, we will first solve for the coalition formation and policy making stage for a given legislature. In the next section we shall look at party formation and study the incentives generated by the parliamentary game for party formation. Thus, in this section we start with a given seat share for each party. There are two stages in the legislative game viz. government formation and policy making.

4.1. The Government Formation and Policy Making game. We assume that each party in the legislature acts as a cohesive decision making unit which tries to maximize the payoff of its representative member. Once the coalition wins the confidence (investiture) vote, policy making and division of the spoils of office is decided by the bargaining among members The bargaining procedure is of course complicated by the fact that we have a non constant sum game. Thus, we do not explicitly model this but simply assume that each members strength is the weight it has in the government and thus they will share the rents from office in that ratio and the implemented policy will be a seat weighted outcome of the members ideal points.

Let $v_{i}(D)$ denote the average payoff of a member of party $i$ when $D$ is the ruling coalition. If $i \notin D$, then $v_{i}(D)=-u\left(\left|x_{i}-x_{D}\right|\right)$ and if $i \in D$, then $v_{i}(D)=-u\left(\mid x_{i}-\right.$ $\left.x_{D} \mid\right)+\frac{1}{s_{D}} P$ where $s_{D}$ is the 'size' i.e. the seat shares of coalition $D .{ }^{8}$ Let $v_{i}(\mathcal{C})$ denote the payoff of a member of party $i$ when there is a consensus government. At the vote of confidence stage, the members of party $i$ will vote for the proposed government $D$ if $v_{i}(D) \geq v_{i}(\emptyset)$ (we assume that when indifferent, a party member votes for the proposed government). Let $A(D)$ denote the set of parties that would vote for the proposed government $D$ and let $s_{A(D)}$ denote its size. If $s_{A(D)}>\frac{1}{2}$, then $D$ forms the government. Let $W$ denote the set of proto coalitions that will win the

\footnotetext{
${ }^{8}$ Note that party $i$ receives $\pi_{i} P$ part of the power. Hence, the per party member share of power is $\frac{\pi_{i} P}{s_{i}}$. Since $\pi_{i}=\frac{s_{i}}{s_{D}}$, we have the per capita share to be $\frac{1}{s_{D}} P$.
} 
vote of confidence. Formally, $W \equiv\left\{D \in 2^{C}\right.$ s.t. $\left.s_{A(D)}>\frac{1}{2}\right\}$. Now we come to the proto coalition selection stage. At this stage the formateur $k$ must choose the proto coalition. Let $Y$ denote the set of proto coalitions that are unanimously preferred by its constituents over the status quo. Formally, $Y \equiv\left\{D \in 2^{C}\right.$ s.t. $\left.v_{i}(D) \geq v_{i}(\phi)\right\}$ Thus, every coalition member has a veto power in that it can decide not to be in the coalition. Hence, unanimity is required among the selected members for a coalition to be formed. Let $D_{k}$ denote the proto coalition most preferred by a member of party $k$, i.e. $D_{k}=\operatorname{argmax}_{D \in W \cap Y} v_{k}(D)$. For simplicity, we assume that $D_{k}$ is unique for each $k$ (otherwise choose with equal probability). Thus, associated with each formateur $k$ we have an equilibrium government $D_{k}$. Formally, a legislative equilibrium can be defined as follows:

Definition 1. A legislative equilibrium is a collection of proto coalition $D_{1}, D_{2}, \ldots, D_{N}$ such that $\forall k \in C, D_{k}=\operatorname{argmax}_{D \in W \cap Y} v_{k}(D)$

Note that existence is not a problem as the sets $W$ and $Y$ are well defined. Hence, $D_{k}$ is well defined.

4.2. Defining different coalitions. Before stating our main results on the parliamentary stage it is useful to make precise the types of coalitions we had described in the introduction. Let $\left(C, S_{i},\left\{x_{i}\right\}\right)$ denote a parliament comprised of $C(>0)$ parties where $S_{i}$ denotes party $i$ 's seat share and $x_{i}$ its ideal point. Let $D \subseteq N$ denote the coalition in power with $\pi_{i}$ denoting the relative seat share of party $i \in D$. Naturally, for $i \in D, \pi_{i}=\frac{S_{i}}{\sum_{k \in D} S_{k}}$. Some special cases of interest are

- $|D|=1$ - a single party is in power.

- $\sum_{k \in D} S_{k} \leq \frac{1}{2}-D$ is a minority government.

- $\sum_{k \in D} S_{k}>\frac{1}{2}$ and $\exists i \in D$ such that $\sum_{k \in D \backslash i} S_{k}>\frac{1}{2}$ - D is a super-majority government.

- $\sum_{k \in D} S_{k}>\frac{1}{2}$ and for any $i \in D, \sum_{k \in D \backslash i} S_{k} \leq \frac{1}{2}-D$ is a minimal winning coalition government. 
- $D=\mathcal{C}$ - a consensus government.

- $\mathcal{C}\left(\left\{x_{i}\right\}_{i \in D}\right)$ denote the convex hull of the ideal points of the coalition partners. If $\exists j \notin D$ such that $x_{j} \in \mathcal{C}\left(\left\{x_{i}\right\}_{i \in D}\right)$ then $D$ is a disconnected coalition. Otherwise $D$ is a connected coalition.

The following section characterizes the types of equilibrium coalitions as a function of policy and power.

\section{A SYMmetric THREE PARTy CHARACTERIZATION AND A 'LIMITING RESUlT'}

Consider a legislature comprised of 3 parties, 1, 2 and 3, with $x_{1}=0, x_{2}=x \leq \frac{1}{2}$ and $x_{3}=1$. We shall further assume that $S_{1}=S_{2}=S_{3}=\frac{1}{3}$. Each party has well defined preferences denoted by a weak ordering $\succ_{i}$ over the set of possible coalitions. If two or more parties prefer a coalition $D$ over the status quo $\{1,2,3\}$, then the $D$ succeeds in forming a government. We will completely characterize the set of equilibrium coalitions.

5.1. Party 2 as the formateur. First suppose that party 2 is chosen as the formateur. It obviously prefers $\{2\}$ over any other $D$ and will succeed in forming the government if $\{2\} \succ_{1}\{1,2,3\}$. 1's payoff from $\{2\}$ in power is $-x$ while his payoff from $\{1,2,3\}$ is $-\frac{1+x}{3}+P$. Hence, 1 will support the coalition if

$$
-x \geq-\frac{1+x}{3}+P
$$

which simplifies to $x \leq \frac{1}{2}-\frac{3}{2} P$. Hence, if the above condition holds, 2 will successfully propose a minority government comprised only of itself. It his condition does not hold, the 2 's other alternatives are $\{1,2\}$ or $\{1,2,3\}$ or $\{1,3\}$. Since $\{1,2\} \succ_{2}\{2,3\}, 2$ will propose $\{1,2\}$ if $\{1,2\} \succ_{2}\{1,2,3\}$ which is equivalent to

$$
-\frac{x}{2}+2 P \geq x-\frac{1+x}{3}+P
$$

which simplifies to $x \leq \frac{2}{7}+\frac{6}{7} P$. Note that 1 will always support $\{1,2\}$ over $\{1,2,3\}$ and hence 2 is assured of winning the vote of confidence. If $x>\frac{2}{7}+\frac{6}{7} P$, then 2 's next 
best alternative would be either $\{2,3\}$ or $\{1,2,3\}$. In either case the government is assured of party 3's support hence support. 2 will propose $\{2,3\}$ if

$$
x-\frac{1+x}{2}+2 P \geq x-\frac{1+x}{3}+P
$$

which simplifies to $x \leq-1+6 P$. Otherwise 2 will prefer the status quo $\{1,2,3\}$.

The following diagram summarizes the various possible coalitions in the $(P, x)$ space.

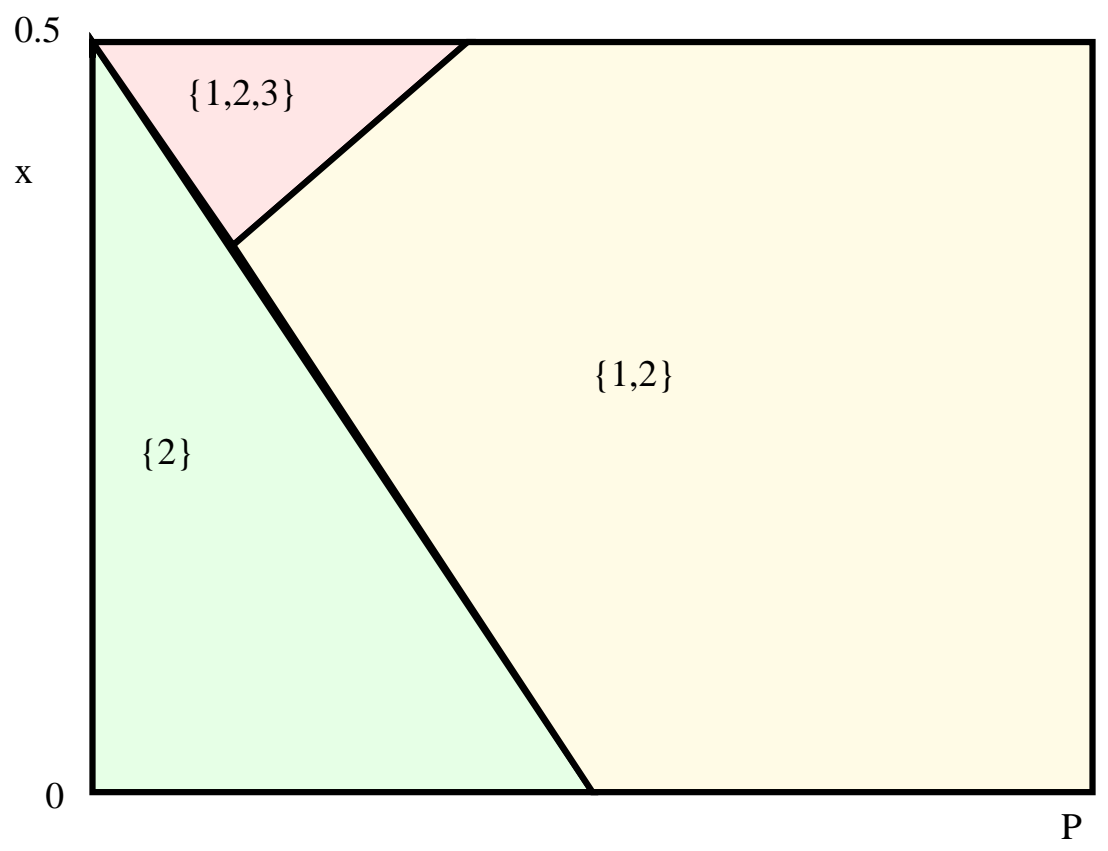

Figure 1. Coalitions with 2 as Formateur

5.2. Party 1 as the formateur. Let party 1 be the formateur. Its most preferred government is $\{1\}$, which it will succeed in forming if $\{1\} \succ_{2}\{1,2,3\}$, which is same as

$$
-x \geq x-\frac{1+x}{3}+P
$$

which simplifies to $x \leq \frac{1}{5}-\frac{3}{5} P$. If the above condition fails to hold, the next best feasible alternative for party 1 is $\{1,2\}$. Party 2 will accept 1 's proposal to form $\{1,2\}$ 
if

$$
-\frac{x}{2}+2 P \geq x-\frac{1+x}{3}+P
$$

which boils down to $x \leq \frac{2}{7}+\frac{6}{7} P$. If neither $\{2\}$ nor $\{1,2\}$ are feasible, then 1 could propose either $\{2\},\{1,3\}$ or $\{1,2,3\}$.

Note that $\{2\}$ will always get party 2 's support. Hence, 1 would propose $\{2\}$ if $\{2\} \succ_{1}\{1,3\}$ and $\{2\} \succ_{1}\{1,2,3\}$. The former condition is equivalent to $x \leq \frac{1}{2}-2 P$ and latter is equivalent to $x \leq \frac{1}{2}-3 P$. Similar conditions can be obtained for the range over which $\{1,3\}$ is the best feasible combination. The following diagram shows the various equilibrium coalitions when party 1 is the formateur.

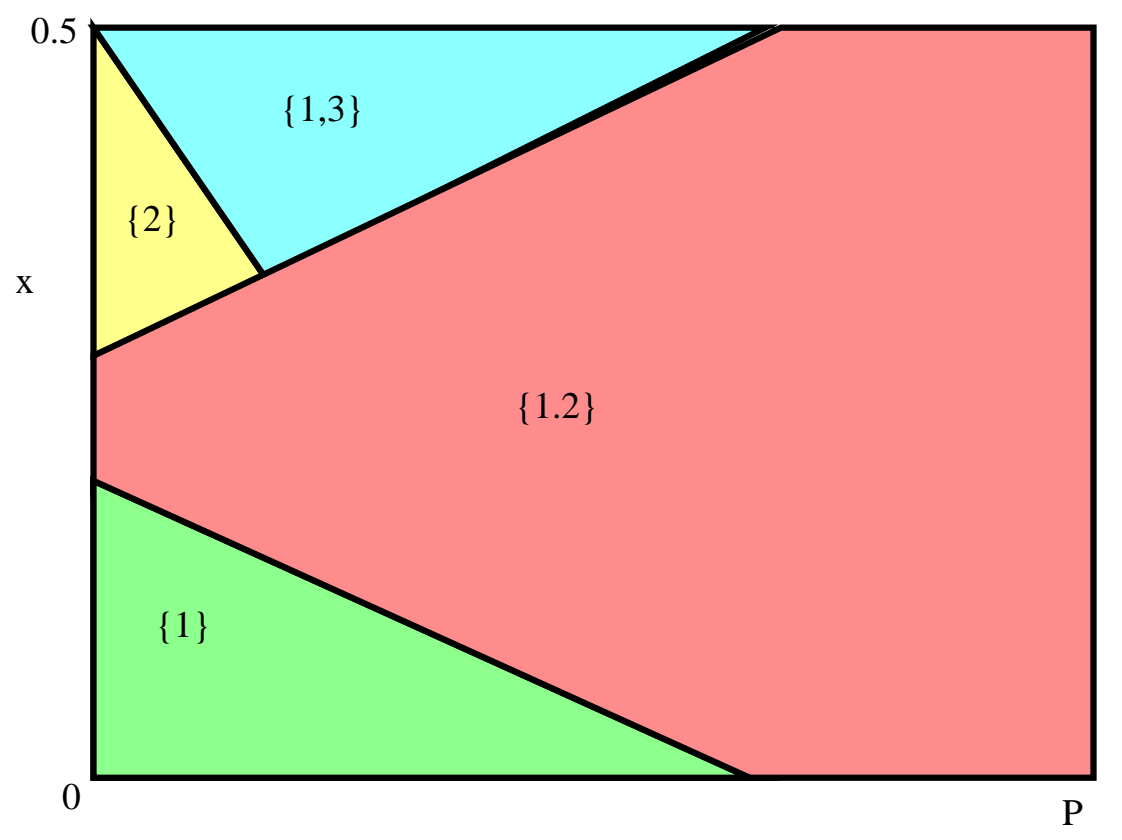

Figure 2. Coalitions with 1 as Formateur

5.3. Party $\mathbf{3}$ as the formateur. To study the possible coalitions when party 3 is the formateur, we do a similar exercise of deriving 3's best feasible coalitions. The following diagram shows the various equilibrium coalitions when party 3 is the formateur. 


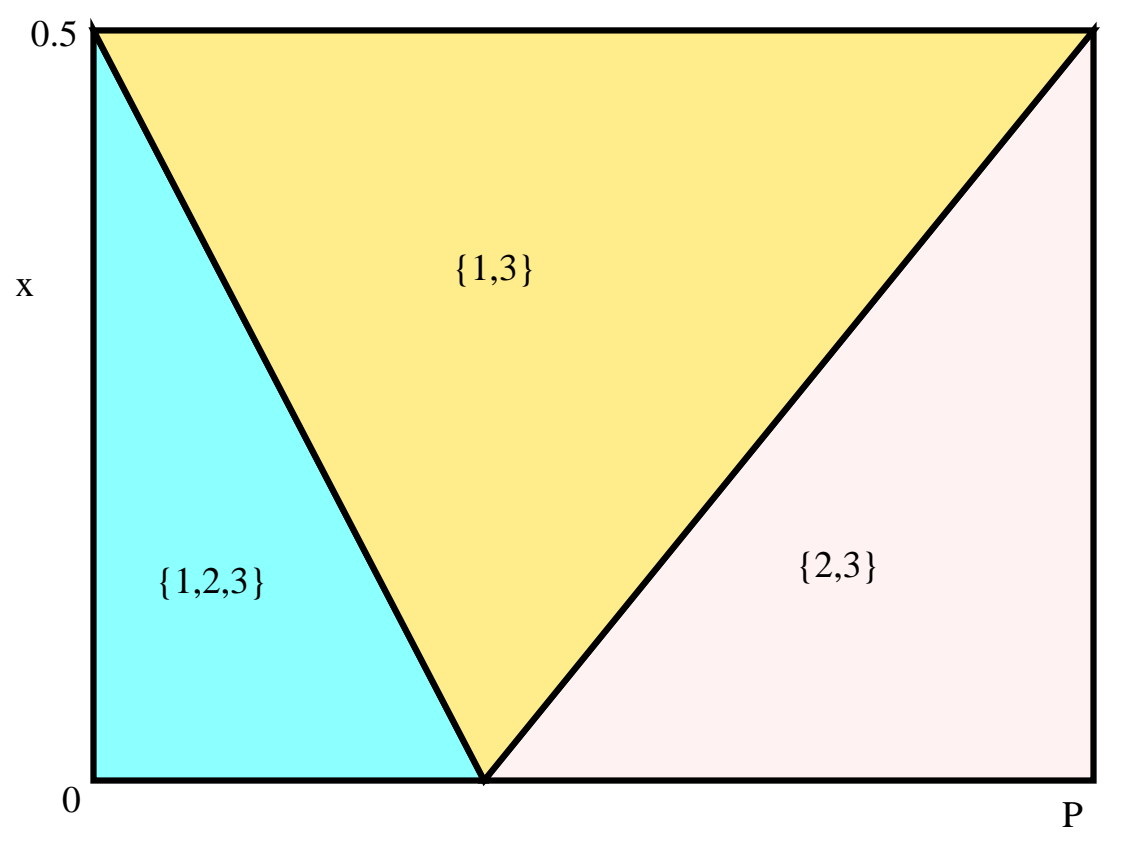

FiguRE 3. Coalitions with 3 as Formateur

5.4. Connected vs. disconnected coalitions. An important insight that the recent empirical work on coalitions has revealed (see Indridason, earlier cit.) is that disconnected coalitions may be more frequently see where ideology is less important as compared to rents (or what we also interpret as special transfers as opposed to policies which affect all groups). To see when this may be true more clearly, consider two particular cases, one where there is a large party which is centrally located and two smaller parties on either side and another where there are two ideologically similar parties with a large party further away from them. We can to fix ideas, assume, as in the symmetric case, that we have parties $1,2,3$ with ideal points $(0, x, 1)$. $S_{2} \geq \max \left(S_{1}, S_{3}\right)$. Thus, essentially we now introduce asymmetry in party size to see how that affects coalition formation. The closer $x$ is to $\frac{1}{2}$, the lower the value of $P$ needed to get a disconnected coalition. Again, as $S_{2}$ gets bigger the chance of a disconnected coalition increases (until $S_{2}=\frac{1}{2}$ ). This captures the intuitive phenomenon that the centrist party is left out as it is asking for too much (in terms of share of 
$P)$. However, this is a special case of a more general result, namely as the value of $P$ gets larger, the equilibrium coalitions are minimum winning (subject to the formateur being in the coalition). Hence, in this case the two smallest parties form a coalition and, being on either side, the coalition is disconnected. On the other hand, when they are on the same side, we can get again get disconnected coalitions when $P$ is very high as the far extreme party will call on the smallest partner which may be farthest from it. In both cases, what is of further interest is to check for consistency with the entry game which we do in the next section.

In this context we note that the general result when the value of rents become very high is that every formateur can form a coalition and that will be minimal winning. We state this formally as follows.

Proposition 1. There exist a value of $P$ beyond which every formateur $i \in N$ can form a coalition and that will be a minimum winning coalition, in particular it will be the smallest minimum winning coalition subject to inclusion of the formateur

Proof. Consider party $i \in N$ and let $M$ denote the smallest minimum winning coalition subject to inclusion of $i$ and denote by $S \geq \frac{1}{2}$ the relative size of the coalition. Denote an alternative larger coalition by $M^{\prime}$ and its relative size by $S^{\prime}$. Note that there exists $P$ for which $u_{M}+\frac{P}{S}>u_{M^{\prime}}+\frac{P}{S^{\prime}}$. Hence, a larger coalition is ruled out. Now we need to show that a smaller coalition will be voted down by a majority. Denote the smaller coalition by $M^{\prime \prime}$ and its relative size by $S^{\prime \prime}<\frac{1}{2}$. It will be voted against by all members not included in $S^{\prime \prime}$ as long as $u_{\phi}+P>u_{M^{\prime \prime}}$. The value of $P$ which satisfies both inequalities is the one beyond which all equilibrium coalitions are minimal winning.

\section{PARTy FORMATiON}

We are now able to define the political equilibrium. We first define the entry stage equilibrium and then the political equilibrium. 
Definition 2. Entry-stage Equilibrium: A profile $e$ of entry decisions constitutes an equilibrium if, for all i $\epsilon C, V_{i}(C)-\delta>V_{i}\left(C^{\prime}\right)$, where $V_{i}(C)$ (respectively $V_{i}\left(C^{\prime}\right)$ ) is the expected utility of party i from contesting (respectively not contesting) and the set of entrants is denoted by $C$ and $C^{\prime}=C-i$.

Definition 3. Political Equilibrium: A political equilibrium is a collection $\left\{D^{*}, e^{*}\right\}$ where $D^{*}=\left(D_{1}, D_{2}, \ldots, D_{N}\right)$ is a collection of equilibrium proto coalitions of the government formation game and $e^{*}$ is an entry-profile such that,

(1) $\forall k \in C, D_{k}=\operatorname{argmax}_{D \in W \cap Y} v_{k}(D)$ and

(2) $e^{*}$ is an equilibrium of the entry game given the proto-coalition decision functions.

6.1. Results. Given these definitions we can now easily show existence.

Proposition 2. A Political equilibrium exists.

Proof. The number of players $(1 \leq N<\infty)$ and the strategy set is finite. Hence, the conditions for existence of a Nash equilibrium holds. In particular, the government formation subgame associated with each formateur also has an equilibrium as $D_{k}$ is well defined.

Now since the entry decision of each party is dependent on the decisions by other parties it is not very difficult to see that we get multiple equilibria. We shall demonstrate this by giving examples of such multiplicity. However, as our next proposition shows, if the median is unique, then the median group being the only group to form a party is always an equilibrium.

Proposition 3. If the median group is unique, there exists a political equilibrium in which the median group stands uncontested and implements its ideal policy in parliament. 
Proof. If the median group forms a party no group can get more than half the votes by standing on its own.

As the median party retains its absolute majority it still becomes the formateur and implements its ideal point. Thus any group $i$ by launching a party incurs a net cost since its change of utility from standing is $U\left(x_{m}\right)-U\left(x_{m}\right)-\delta=-\delta<0$. Hence, no unilateral deviation is profitable. Any group by forming a party only undergoes a cost..$^{9}$

It is natural at this stage to ask what (if anything) can be said about Duverger's law. Non-Duvergerian predictions for PR have been made (see the papers cited in section 2), in particular showing that only two parties can form under PR. The assumptions are open to question but clearly it is worth investigating if strategic entry in our particular framework can give rise to non Duvergerian predictions. An interesting point in this context made by Morelli (earlier cit.) is that in a multidistrict model if the population distribution across districts is sufficiently dissimilar Duverger's predictions are reversed. We demonstrate that even in a one district scenario we can get more parties under plurality voting than under PR.

There are three groups with ideal points $0, x<\frac{1}{2}, 1$. We further assume that $N_{i}=$ $\frac{1}{3} \forall i$. We wish to look at conditions under which the median group forming the party is the unique equilibrium. In other words, contra Duvergerian prediction we have only one party under PR. We also examine under what conditions we have another equilibrium in which all the groups will stand. To understand why the unique equilibrium could be party with ideal point $x$ standing, note that the group further away from $x$ (i.e. the party with ideal point 1 ) may wish to withdraw in order to prevent the minimum winning coalition of $0, x$ which will be worse for the group than if the ideal policy of the middle group $x$ is implemented. The conditions that need

\footnotetext{
${ }^{9}$ This is not robust in the sense that it depends on the simultaneity of the game. Note that this non robustness is true for the citizen candidate model as well.
} 
to be satisfied for this is that the equiprobable chance of the three coalitions that occur when all three groups form parties must be less than the utility from $x$ being implemented with certainty. In this, we have different cases to consider. The first is when there a coalition between the parties with ideal point 0 and 1 when the party with ideal point 0 is the formateur and a minority government when the party with ideal point $x$ is the formateur and a caretaker government when the party with ideal point 1 is the formateur.

Proposition 4. Let there be three equal sized groups, 1,2 and 3 with the ideal points given by $0, x<\frac{1}{2}, 1$, respectively. Further assume that $\left|\frac{x}{2}\right|<\left|\frac{x+1}{3}-x\right|<|x|$. There exists a unique political equilibrium where the party with ideal point $x$ contests when the following conditions hold (1) $-\frac{1}{3}\left|\frac{x+1}{3}-1\right|-\frac{1}{3}\left|\frac{x}{2}-1\right|-\frac{1}{3}|x-1|+\frac{P}{3}-\delta<-|x-1|$ (2) $3 P-3 \delta \geq \max \left\{u_{\emptyset},-x,-(1-x)\right\}$ where $u_{\emptyset}$ denotes the payoff when no party runs for elections.

Proof. The assumption $\left|\frac{x}{2}\right|<\left|\frac{x+1}{3}-x\right|<|x|$ implies that if all three groups have contested (and by sincere voting gained equal seat shares in the legislature) the party with ideal point 0 as formateur will from a minimum winning coalition with the party with ideal point $x$, while the party with ideal point $x$ will form a minority coalition at low values of $P$ and the status quo will be implemented when the party with ideal point 1 is the formateur. Clearly, this is not restrictive in that in the event that the party with ideal point 0 can form a minority government, the incentive for the party with ideal point 1 to drop out is even greater. Given that, we see by condition (1) that the group with ideal point 1 prefers to drop out which leads to the policy $x$ being implemented with certainty. Condition (2) makes sure that group 2 would always like to form a party and contest the elections.

The intuition for this is that the further extreme party (with ideal point 1) prefers $x$ as the policy than a coalition which would lead to $\frac{x}{2}$ being the policy and hence drops out to give the middle party a majority. Thus, while several formalizations of 
Duverger's law relied on voters behaving strategically (see references earlier cit.), we have shown that even with sincere voting the intuition is not very different if there is strategic behavior on the part of parties. In particular, notice that the condition for uniqueness under PR is weaker than that under plurality voting (PV) in the sense that under PV $-\frac{1}{3}\left|\frac{x+1}{3}-1\right|-\frac{1}{3}\left|\frac{x}{2}-1\right|-\frac{1}{3}|x-1|+P-\delta<-|x-1|$ would need to hold as in the event of a tie there is a on third probability of the party with ideal point 1 being the winner and hence appropriating all the $P$.

We now look at entry-proofness for the two asymmetric cases described in the discussion on connected vs. disconnected coalitions. Recall that we had three parties $1,2,3$ with ideal points $(0, x, 1) . s_{2} \geq \max \left(s_{1}, s_{3}\right)$ The closer $x$ is to $\frac{1}{2}$ the lower the value of $P$ to get disconnected coalitions. Again ;as $s_{x}$ gets bigger chances of a disconnected coalition increases (until $s_{2}=1$ ). We can see why at low $P$ and reasonably moderate $\delta$ an extreme party may want to drop out.

Now consider the three parties $1,2,3$ with ideal points $(0, x, 1)$ with $s_{3} \geq \max \left(s_{1}, s_{2}\right)$. It is easy to see that with low $P$ the status quo is implemented. As an example of entry (non proofness) consider $x=\epsilon$ close to 0 . It is easy to see that there exists $P$ such that

$$
-\left|s_{2} x+s_{3}-x\right|+\frac{P}{3}>-\left|\frac{1-x}{2}-x\right|+\frac{P}{2}
$$

But notice that this is not entry proof. This is because $-|x|>-\frac{1}{3}\left|s_{2} x+s_{3}-x\right|+$ $\frac{P}{3}-\frac{1}{3}|x|+\frac{1}{3} P-\delta$ for $x$ close to 0 .

Note of course that as $P$ gets very large there exist a political equilibrium in which all groups contest. The following proposition formalizes this.

Proposition 5. There exist a value of $P$ such that all $N$ groups contesting the elections is a political equilibrium as long as there does not exist a group $j$ such that $N_{j}>\sum_{i \backslash j} N_{i}$.

Proof. We know that there exist a value of $P$ at which any formateur $i$ can form a minimal winning coalition including itself. We need to show that there exist a value 
at which in an equilibrium with all $N$ groups forming parties, no one will deviate. The minimum loss (assuming party $i$ is in government only if selected to be a formateur) to a party $i$ by withdrawing is $\frac{P}{N}-\delta+E u_{N}-E u_{N-i}\left(E u_{N}-E u_{N-i}\right.$ denotes difference in expected utility in terms of ideology implemented if party $i$ withdraws) which is $>0$ for large $P$.

\section{Multidimensional Analysis And COMparison with the Baron DiERMEIER MERLO'S EFFICIENT BARGAINING}

So far we have done a one dimensional analysis. The models of BDM (earlier cit.) consider scenarios where there are two policy dimensions and characterize a 'symmetric case' with three parties which are equidistant from each other. While the two dimensional model they use can be analyzed in our framework as well, the one dimensional analysis allows us to look at the issue of 'connectedness' ${ }^{10}$ of coalitions and develop comparative static results with regard to how equilibrium coalitions could change (from connected to disconnected or vice versa) as a function of seat share, ideological closeness and the value of the rents from office. In this section we provide a two dimensional characterization for a symmetric 3 party case which would also facilitate comparison with BDM. We also comment on the differences in the results that they obtain with our results for the same set of ideal points. Following BDM let the ideal points of party 1,2 and 3 be located on the vertices of an equilateral triangle with the coordinates being respectively $(0,0),(1,0)$ and $\left(\frac{1}{2}, \frac{\sqrt{3}}{2}\right)$. To make things comparable we assume that $s_{i}=\frac{1}{3}$ for all $i$. We divide the regions by drawing lines from the party's ideal points which cross at the centroid of the triangle.

Following our choice of status quo, we have $x_{\phi}=\left(\frac{1}{2}, \frac{\sqrt{3}}{6}\right)$.We will show that regardless of the identity of the formateur and the value of $P$ minimal winning coalitions emerge. Further, the formateur is indifferent to the choice of a coalition partner. The intuition is simple enough. Any formateur is unable to form a minority government

\footnotetext{
${ }^{10}$ In multidimensional space, defining 'connectedness' itself is difficult.
} 


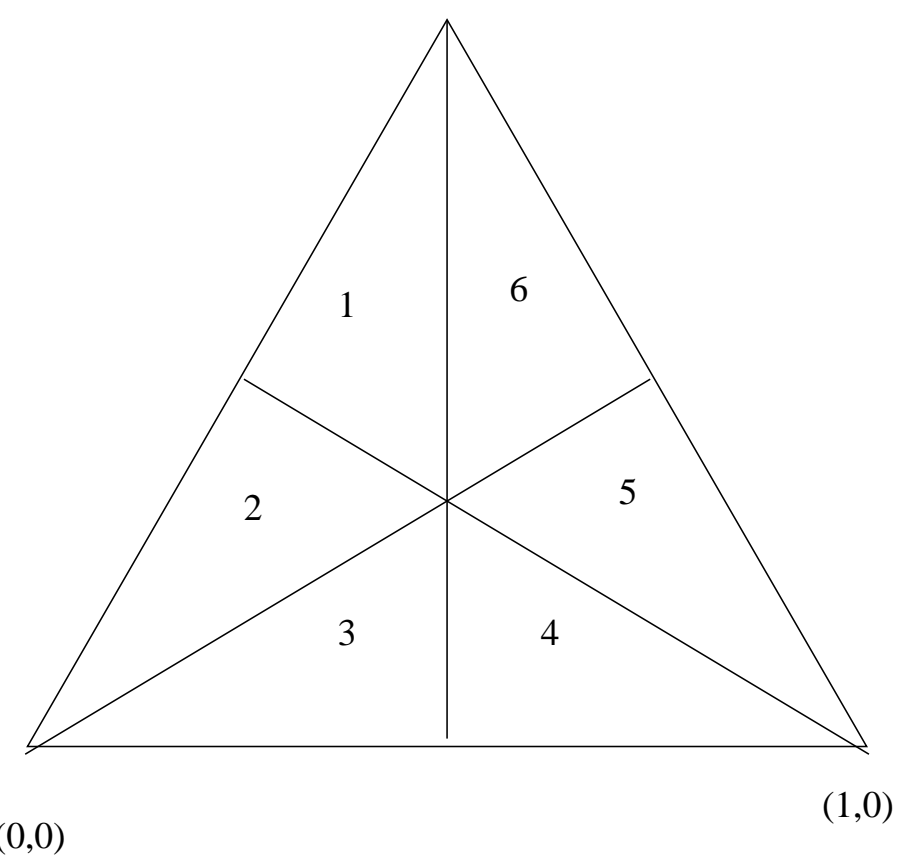

Figure 4. 2 Dimensional Case

as the other partners prefer the status quo policy to the formateur's ideal point. However, any party asked by the formateur is willing to join as the compromised policy (which is midway between them) is preferred by both to the status quo. This goes through for any value of $P$ as the seat shares are the same and there is thus no effect coming from wanting to take a smaller party. We formalize this in the following proposition.

Proposition 6. Let there be three parties 1,2,3 of equal size and two policy dimensions $x$ and $z$. Further, let the parties have policy positions given by $(0,0),(1,0)$ and $\left(\frac{1}{2}, \frac{\sqrt{3}}{2}\right)$ respectively. Let the utility function for party $i$ be given by $-\frac{1}{2}\left(y_{1}-x_{i}\right)^{2}-$ $\frac{1}{2}\left(y_{2}-z_{i}\right)^{2}+\lambda P$, where $y=\left(y_{1}, y_{2}\right)$ is the implemented policy. Then, for any formateur $i \in 1,2,3$ the equilibrium government will be minimum winning. Further, $i$ will be indifferent to the choice of a coalition partner. 
Proof. As the parties are located symmetrically, we can consider the case where 1 is the formateur without loss of generality. In that case 1 can propose to either 2 or 3 and in each case the utility both to the formateur and the other party will be $-\frac{1}{4}+\frac{P}{2}$. Now the utility from the status quo which is $\left(\frac{1}{2}, \frac{\sqrt{3}}{6}\right)$ (to both parties) will be $-\frac{1}{3}+\frac{P}{3}<-\frac{1}{4}+\frac{P}{2}$. Hence this proposal will be accepted by whoever the formateur invites. Clearly, this also rules out supermajoritarian governments as the policy (in this three party case) is the same as the status quo policy. Now, we only need to check that a formateur cannot propose a minority government. This is also easy to see as the minority government yields a utility of -1 for the two excluded parties which is less than $-\frac{1}{3}+\frac{P}{3}$. Hence, the minority government will be voted against by the two excluded parties. Notice, that the results are the same whoever is chosen by the formateur in the minimum winning coalition as the three parties are equidistant from each other. Hence, the formateur is indifferent to a choice of coalition partner.

This result contrasts with both the papers. In the static version of Diermeier and Merlo, only minority and surplus (supermajoritarian) coalitions occur. That is because of the particular status quo they take. Diermeier and Merlo constrain the status quo $x_{\phi}$ to lie in the set $\left(\left(x_{1}, y_{1}\right),\left(x_{2}, y_{2}\right),\left(x_{3}, y_{3}\right)\right)$. Baron and Diermeier (2001) have an arbitrary status quo, in general their status quo can lie in one of the six partitions of the triangle or even outside it. They get minimum winning coalitions except when the status quo is very outlying. The reason is that with an outlying status quo, coalition partners (in their framework) are willing to make large transfers to be in the government.

An important distinction in our approach as compared to BDM is worth mentioning. For large enough $P$ we necessarily get minimal winning coalitions subject to the inclusion of the formateur. In other words when the value that parties place on rents (or directed transfers to their own groups) as compared to ideology, we converge to the prediction of Riker subject to inclusion of the formateur On the other hand, the 
choice of coalition in BDM is driven by the status quo and is independent of the value of $P$ increasing. Hence, even when $P$ is very large they do not converge to Riker's prediction. Both approaches have merit, however because of 'efficient bargaining' BDM are unable to analyze how coalition structure varies as the relative importance of ideology to 'rents from office' change. It is also worth noting that they also ignore any endowment constraints. They analyze $P$ as perks which can be freely transferred but they do not analyze what happens when the value is small so that the transfers required for the efficient outcome cannot be made. In other words, their results would vary when the constraint becomes binding (i.e. $P$ is low).

The arbitrary status quo chosen by BDM can be generated as the status quo in our model for different seat shares as long as it lies inside the triangle. However, all points inside are not really admissible for coalition formation as $s_{i}>\frac{1}{3}$ for those points to be a status quo in our model. A comparison can of course be carried out for an arbitrary status quo in the BDM framework and compare it to what happens if we replace their assumption of full commitment and perfect transferability with the 'no commitment' assumption that we use in our model. To rule out issues of how $P$ would be divided we set it to 0 . We find that even when we consider the status quo chosen by BDM in the two papers we get different results if we assume no commitment. We first analyze the case. where the status quo is the policy of any one of the parties.. In that scenario, there are two cases to consider, one where the policy of the formateur $i$ is the status quo and another where $j \neq i$ is the formateur. In the first case it is easy to see that $i$ proposes a minority government including only itself and all parties support it as they are indifferent to the government's policy and the status quo $x_{\phi}$ which are the same. In the second case the proposer $j$ also proposes a minority government and is supported by the party which is different to $j$ 's policy and the status quo as they are equidistant. Hence, the results in the static version of their paper gives only minority governments under our assumptions. 
Now, consider the more general case which It is easy to show that only minority or minimal winning governments can form. In each of these six regions (and assuming $x_{\phi} \neq x_{i}$ ) if the party closest to the status quo is the proposer a minimal winning coalition forms and the proposer is indifferent to the identity of the other coalition partner.

\section{Robustness: How CRITICAl ARE the Assumptions?}

In this section we study the robustness of the equilibrium to the assumptions we made about parliamentary rules (formateur selection procedure/ bargaining outcomes), voting behavior and inability of parties to commit to positions other that their ideal points. We will not deal with the last two issues except make brief remarks about each. However, we shall talk in some detail about two alternate ways to model legislative behavior which are common in the literature.

8.1. Majority Rule game. Instead of the formateur selection and coalition formation procedure suppose Parliament operated by voting on each issue by majority rule. In a single dimensional policy space this would lead to the Condorcet winner. If a single issue is what matters to the groups we get fairly sharp results for the whole political process. Consider the arbitrary $\mathrm{N}$ groups and assume a unique median exists. In that case we get the following results immediately.

Proposition 7. If after elections the median of the candidates (representing different party positions) is implemented, at most two groups put up candidates in equilibrium.

Proof. First, note that more than two candidates standing cannot be an equilibrium. To see this note that if three (or more) candidates contest in the second stage there will be at least one candidate who will be non pivotal i.e. whose dropping out will not affect the implemented policy. hence, it is not optimal for that candidate to contest.

We now show that there can be zero, one or two candidate equilibria.

If cost are very high it is easy to see that no candidate will stand. 
To get one candidate equilibria first note that there exists a $c$ for which if the candidate with ideal point 0 stands, for all $\epsilon, 1-\epsilon$ will not find it worthwhile to contest and win This implies that $u(-1+\epsilon)>P-c$. This implies a continuum of one candidate equilibria where any candidate can stand in equilibrium. However, as $c$ decreases the range decreases i.e. the marginal candidate who can stand uncontested moves towards the median. Further, as $c$ decreases we can get two candidate equilibria symmetrically around the median. ${ }^{11}$

Notice, that this contrasts with Duverger's hypothesis that PR leads to a multiparty (more than two) system. Moreover, this range around which symmetric 2 candidate equilibria can occur also keeps shrinking.

Proposition 8. As costs go to zero (and the median is unique) the unique equilibrium is for the median citizen to form a party.

Proof. We need to consider only one candidate or two candidate equilibria.

Consider a 1 candidate equilibrium with a group $x_{i} \neq x_{m}$ where $x_{m}$ is the ideal point of the median candidate. WLOG, let $x_{i}<x_{m}$. Clearly, any $j$ such that $x_{i}<x_{j} \leq x_{m}$ can form a party and get more than half the votes. The net gain to group $j$ is $U\left(x_{j}\right)-U\left(x_{i}\right)+P-\delta>0$ when $\delta \rightarrow 0$.

Now consider 2 candidate equilibria. We already know that they must be symmetric around the median. Let us denote the utility to the median group in these symmetric equilibria by $U\left(x_{s}\right)$. Since, the post election policy gets selected by majority rule, if the median group deviated and formed a party it will get its ideal point in stage 2 . Hence, by deviating the median group gets $U\left(x_{m}\right)-U\left(x_{s}\right)+P-\delta>0$ when $\delta \rightarrow 0$.

\footnotetext{
${ }^{11}$ We have assumed that the group sizes are the same for convenience and they are at the same distance from their neighbors, hence 2 candidate equilibria are possible. Otherwise, as we have shown before we need to introduce voter uncertainty to get 2 candidate equilibria.
} 
We already know that the median group being the only group to form a party is an equilibria. We have shown no other equilibria exists. Hence, as cost go to zero this is the unique equilibrium.

A comparison with plurality voting is quite interesting. For different cost levels we get one or two candidate equilibria as in the citizen candidate model with plurality voting. As cost decrease our prediction is extremely sharp under PR unlike plurality voting and it predicts a unique outcome. However, this seems hardly representative of how Parliament works. In particular, even if this were taken to be a way to make decisions we run into problems if the policy space is multidimensional. Different results obtain depending on how voting on different issues take place.

8.2. Selection in order. Another rule which is sometimes seen in formateur selection (and mandated by law in Greece) is selection in order analyzed by Austen Smith and Banks (earlier cit.). We now look at ex post coalitions under the 'Selection in order' rule (Austen Smith and Banks Protocol). Briefly, this involves a fixed order of asking parties to be the formateur-starting with the largest (in terms of vote shares) and then if the largest fails to form a government the second largest and so on. If all parties fail a national government is formed and the policy implemented is a status quo policy which is implemented by a caretaker government which enjoys no power.

We now present some results which contrast with random selection.

Proposition 9. If power and entry costs are low the unique equilibrium of the political game is for the median group to be the unique party to form.

Proof. We first show that if power is 'low' in the parliamentary game only the median party will be able to command a majority support. This is because any coalition will have an implemented policy $x_{j} \neq x_{m}$ where $x_{m}$ is the median party's ideal point. Hence, a majority of members prefer $x_{m}$ to $x_{j}$. Hence, the optimal coalition when the median party proposes is for it to propose a coalition consisting only of itself which 
will be accepted. Therefore, the unique equilibrium of the parliamentary game is for $x_{m}$ to get implemented.

Clearly, if this is the outcome in the legislature no other group will launch a party in the party formation stage.

Proposition 10. If the status quo policy $x_{\phi}$ is implemented by a caretaker government which enjoys no power, that government will not form in equilibrium.

Proof. We are required to show that at least 1 party can form a successful coalition when it is the formateur. Notice that as $x_{\phi}$ lies between $x_{1}$ and $x_{n}$ a coalition of the median party is preferred by a majority to the status quo. So there exists a feasible coalition which dominates the status quo.

We notice that this result contrasts with that under proportional selection. In fact, while caretaker governments are not unheard of it is usually the case that even though governments may not form at the first attempt it is almost always the case that some coalition comes to power. The one shot version of the random recognition protocol by cutting off the game in one stage does not allow for any other party to get a chance to propose leading to this 'extreme' situation. A further insight that we get is the following.

Corollary 1. An extreme party cannot form a minority government.

Proof. To see this notice that the middle party's minority government is preferred by a majority of members. Thus there exists at least one coalition which Hence, parties commanding a majority of seats will not accept the proposal of a minority government by an extreme party.

A couple of remarks at this point are in order.

Remark 1. Minimal winning, minority and surplus governments are possible in equilibrium. Moreover, the coalitions may be connected or disconnected. 
The trade-offs involved are similar to the proportional selection model.

Remark 2. The first party may not be able to form a coalition. Hence, delays may occur in equilibrium. However, it is worth noting that for every equilibrium involving delay there is an equilibrium without delay which leads to the same government.

Notice that the formateur may not be able to form a government including itself and hence the offer it makes to other parties to join a coalition with it will be turned down. However, an equivalent outcome can be achieved by the formateur proposing a coalition excluding itself which lies in $W \cap Y$.

Some points of difference are worth noting.

First, in the random recognition protocol we may get caretaker governments as well as minority governments. Selection in order never leads to a caretaker government in equilibrium. Moreover, only a median party can form a minority government and that too only when power is very low. At the empirical level, while selection in order is not borne out, it is worth investigating if the predictions of the one period random recognition model used in recent papers by BDM which we have adopted here as well captures important features of the data. Clearly, finite periods of these protocols change the results but it is still not clear what institutional details correspond to this random recognition protocol. Thus, when the largest party is not selected we need to see if this is because a party other than the largest has indicated that it has the support of other parties which would enable it to form a government. Another important thing to look at is how well the 'random recognition' model fits the data after accounting for an incumbency bias i.e. where the last party in power is first asked to form the government. The 'selection in order' protocol is something that can be observed and legislated on (as in Greece). However, there is certainly a lot to be said for this 'random selection' procedure in terms of capturing the inherent uncertainty that is associated with the political environment in government formation 
in most countries. Moreover, this random selection model of BDM we have analyzed under modified assumptions leads to fairly interesting results.

Clearly, there are issues which are important in the political process which we have left out. For instance, we do not consider the issue of strategic voting. As long as representation per se is important, there are less reasons for voters to behave strategically under PR than under plurality. There is enough evidence in the recent runoff in the French Presidential elections to believe that voters behaved sincerely. ${ }^{12}$ Further work is certainly needed in this area. We have embedded a citizen candidate model in the institutional framework of coalition government formation. Thus, we do not allow parties to credibly commit to positions other than their own. Given that parties may have access to a credible commitment device (often repeated play ensures that, see Alesina (earlier cit.)). it would be interesting to see if this would lead to more divergence or more convergence of party policies. This remains a fascinating area of future research.

\section{EMPIRICAL RELEVANCE AND CONCLUDING REMARKS}

We have presented a model of parliamentary democracy under PR which predicts political coalition formation as a function of party size and the relative importance of power to ideology. Moreover, by endogenizing the political entry stage we have shown how our legislature is consistent with a party formation game under the assumption of sincere voting. Our coalition and policy making stages in particular give rise to certain predictions which contrast with those existing in the literature. In particular, two limiting cases arise, one when parties care only for ideology and another where the rents of office become very large. We find that in the limit Riker's size principle does apply subject to inclusion of the formateur and coalitions are minimal winning

\footnotetext{
${ }^{12}$ Candidates to the left of Jospin received enough votes which, if combined, could have ensured Chirac's defeat.
} 
(though not minimum size) when the vale of rents from office become very big. However, because we explicitly consider party size, 'disconnected coalitions' can occur even with parties which are purely driven by ideology. Thus, when parties care only for ideology they may leave out an ideologically close partner because a large party can tilt the policy too close towards its ideal point because of its increased bargaining strength.

We can usefully compare our paper to the papers by BDM which use efficient bargaining and perfect commitment within the coalition. Given any coalition, our model predicts a policy orientation that is skewed towards larger parties while BDM predicts that party size will be irrelevant. This stems from the bargaining procedure in BDM giving equal weights to all parties. With different weights in proportion to size, our results in this regard will match. The more fundamental difference comes from the assumption of no commitment which leads to substantive differences in predictions for coalitions for a given a composition of the legislature. Empirically, we do not believe that perfect commitment or the converse are observed. However, our results are robust to some degree of commitment. We believe that apart from the usefulness of analyzing the polar opposite of BDM, no commitment at the coalition formation stage is often a good approximation-this implies that the proposer cannot make a take it or leave it offer such that anything in the status quo's majority win set would be accepted. This seems consistent with the observed phenomenon of power sharing that is seen in coalitions around the world. As we had pointed out earlier Laver and Schofield (earlier cit.) state that cabinet seats being allotted roughly in proportion to seat shares is one of the most observed empirical regularities of coalition governments. They also provide a discussion for why at the coalition formation stage the manifestos written are not binding and that actual policies are a result of intricate bargaining inside the coalition. ${ }^{13}$ Hence, both as an approximation to what happens

\footnotetext{
${ }^{13}$ See also Laver and Shepsle (1995).
} 
in the real world and in terms of predictive power we argue that no commitment is not a bad assumption.

Another issue that we address, but which BDM cannot (because of their assumption of efficient bargaining) is the ideological connectedness of coalitions as functions of power. We are not aware of too many studies which look at this systematically. A paper by Indridason (2001) examines the nature of disconnected coalitions in the context of a few northern European countries and tentatively concludes that this is related to whether the office seeking model is more appropriate or whether the coalition is governed by ideological considerations. Our model makes a set of predictions which are more precise and can provide a useful basis for further case studies along these lines. In fact, another recent paper by Indridason $(2003)^{14}$ presents some empirical tests on 'clientelism' and coalition structure. While his 'clientelism' may not be the only way to think about we call political power, it provides an interesting set of hypothesis about how coalition structure depends on the degree of 'office seeking' motives of politicians. It is certainly worth looking at some of our predictions using the same dataset.

An extremely important issue is the formateur selection procedure. Diermeier and Merlo (2001) provide the first systematic empirical study but they study only the first stage i.e. they look at whether it is the case that the first party is always asked to form the government against the alternate that this is roughly in proportion to seat shares and find empirical support for the latter. However, some things are worth further investigation-when the party elected to be the formateur is not the largest it is worth looking at whether they have informally waived the right to form the government. Moreover, whether it is the case that the party selected to be the formateur has an informal pre electoral understanding with a set of parties which together can win a majority in parliament. Also, given an incumbency bias in selection we need to check

\footnotetext{
${ }^{14}$ Kalandrakis (2002) also does an empirical analysis of coalitions though his empirical analysis is restricted to minority governments.
} 
how well the two alternatives perform after controlling for that. Another issue worth pursuing is to see how well proportional selection fits the data after controlling for the number of parties. These issues together with a more specific procedure incorporating institutional details of bargaining among parties inside a coalition will lead the way to a more complete understanding of formateur selection considerations as well as why delays in bargaining over government formation occur. 


\section{References:}

AMY, D. (2000), 'Real Choices/New Voices: The Case for Proportional Representation Elections in the United States', Columbia University Press.

ANSOLABEHERE S., J. SNYDER, A. STRAUSS and M. TING (2003), 'Voting Weights and Formateur Advantages in the Formation of Coalitional Governments' (mimeo)

AUSTEN-SMITH, D. and J. BANKS (1988), 'Elections, Coalitions, and Legislative Outcomes', The American Political Science Review, Vol. 82, No. 2, June, pp. 405-422.

AXELROD, R., (1970), 'The conflict of interest', Chicago, Marham.

BARBER, K. (1999), 'A Right to Representation :Proportional Election Systems for the Twenty-first Century' Ohio State University Press.

BARON, D. and J. FEREJOHN (1989), 'Bargaining in Legislatures', The American Political Science Review, Vol. 83, No. 4, December, pp.1181-1206.

BARON, D. (1989), 'A non cooperative theory of legislative coalitions', American Journal of Political Science, Vol.33, No.4 pp. 1048-84.

(1991), 'A Spatial Bargaining Theory of Government Formation in Parliamentary Systems', The American Political Science Review, Vol. 85, No. 1, March, pp. 137-164.

(1993), 'Government Formation and Endogenous Parties', The American Political Science Review, Vol. 87, No. 1, March, pp. 34-47.

(1998), 'Comparative Dynamics of parliamentary Governments' The American Political Science Review, Vol.92, No.3, September, pp. 553-609.

and D. DIERMEIER (2001), 'Elections, Governments, and Parliaments under Proportional Representation', Quarterly Journal of Economics, Vol. 116 Issue 3 August, pp. 933-967

BESLEY, T. and S. COATE (1997), 'An Economic Model of Representative Democracy', Quarterly Journal of Economics, Vol. 112, No. 1, pp. 85-106 
BRAMS, S., M. JONES and D. KILGOUR (2001) 'Single peakedness and Disconnected Coalitions', Journal of Theoretical Politics (forthcoming)

BROWNE, E. and J. FRENDREIS (1980), 'Allocating Coalition Payoffs by Conventional Norm: An Assessment of the Evidence from Cabinet Coalition Situations' American Journal of Political Science, Vol. 24, No. 4. November, pp. 753-768.

BLOCH, F. (1997) 'Noncooperative Models of Coalition Formation in Games with Spillovers, Chapter 10 in New Directions in the Economic Theory of the Environment (C. Carraro and D. Siniscalco eds.), Cambridge University Press.

DHILLON, A. (2003) 'Political Parties and Coalition Formation' mimeo (forthcoming in "Group Formation in Economics: Networks, Clubs and Coalitions", edited by G Demange and M.Wooders, forthcoming, Cambridge University Press.

DIERMEIER, D., M. KEANE and A. MERLO (2002) 'A Political Economy Model of Congressional Careers', UPenn Working Paper.

DIERMEIER, D. and A. MERLO (2000), 'Government Turnover in Parliamentary Democracies', Journal of Economic Theory, Vol. 94, September, pp. 46-79. (2001), 'An Empirical Investigation of Coalitional Bargaining Procedures', UPenn Working Paper.

DOWNS A. (1957) 'An Economic Theory of Democracy' New York: Harper Collins.

DUTTA, B., M. JACKSON and M. LE BRETON (2001), 'Strategic candidacy', Econometrica, Vol.69, No.4, pp.1013-1037

DUVERGER, M. (1964), 'Political parties: their organization and activity in the modern state', 3rd edition, Methuen Press, London.

FEDDERSEN, T. (1992), 'A Voting Model implying Duverger's Law and Positive Turnout', American Journal of Political Science, Vol.36, No.4, pp. 938-962.

FEY, M. (1997), 'Stability and Coordination in Duverger's Law: A Formal Model of Preelection Polls and Strategic Voting', American Political Science Review, Vol.91, pp. $135-147$. 
GALLAGHER K., K. LAVER and P. MAIR (1995), 'Representative Government in Modern Europe', New York Mc Graw Hill.

HAMLIN A. and M. HJORTLUND (2000), 'Proportional Representation with Citizen Candidates', Public Choice, Vol. 103, No.3, pp. 205-230.

INDRIDASON, I. (2001), 'A Theory of Coalitions and Clientelism: Coalition Politics in Iceland 1945-2000.', Working Paper, Department of Political Science, Michigan State University.

(2003). 'Coalitions and Clientelism: A Comparative study', mimeo

JACKSON M. and A. MOSELLE (2002) 'Coalition and Party Formation in a Legislative Voting Game', Journal of Economic Theory, Volume 103, No.1, pp.49-87

KALANDRAKIS, T. (2002) 'Minority Governments: Ideology and Office', mimeo

KONISHI H. and D. Ray (2003) 'Coalition formation as a dynamic process' Journal of Economic Theory, 110, 1-41

LAVER, K. and N. SCHOFIELD (1990), 'Multiparty Governments: The Politics of Coalitions in Europe', Oxford University Press.

LAVER, K. and K.SHEPSLE (1996) 'Making and Breaking Governments: Cabinets and Legislatures in Parliamentary Democracies. New York: Cambridge UP.

LEVY, G. (2002) 'A Model of Political Parties' Journal of Economic Theory (forthcoming)

LUPIA, A. and KAARE S. (1995) 'Coalition termination and the strategic timing of parliamentary elections', The American Political Science Review, Vol.89, pp. 648-665.

MORELLI, M. (2001), 'Party Formation and Policy Outcomes Under Different Electoral Systems', Working paper.

ORTUÑ̃-ORTÍN, I. (1997), 'A spatial model of political competition and proportional representation', Social Choice and Welfare, Vol.14, No. 3, pp. 427-438. 
OSBORNE, M. and A. SLIVINSKI (1996), 'A Model of Political Competition with Citizen-Candidates', The Quarterly Journal of Economics, Vol. 111, No. 1, February, pp. 65-96.

OSBORNE, M. and R. TOURKY (2002), 'Party formation in collective decision-making', Working paper.

PALFREY, T. (1989), 'A Mathematical Proof of Duverger's Law' in P.C. Ordeshook (ed.) Models of Strategic Choice in Politics, University of Michigan Press.

RAY. D. and R. VOHRA (1997) 'Equilibrium Binding Agreements' Journal of Economic Theory 73, 30-78

(1999) 'A Theory of Endogenous Coalition Structures', Games and Economic Behavior, 26, 286-336

RIKER, W. (1962) 'The Theory of Political Coalitions' New Haven, Yale University.

RIVIERE, A. (2000), 'Citizen Candidacy, Party Formation and Duverger's Law', Discussion Paper, Royal Holloway, University of London

ROEMER, J. (2001), 'Political competition: Theory and Applications' (Harvard University Press) 